\title{
sciendo
}

\author{
Current Issues in Pharmacy and Medical Sciences \\ Formerly ANNALES UNIVERSITATIS MARIAE CURIE-SKIODOWSKA, SECTIO DDD, PHARMACIA \\ journal homepage: http://www.curipms.umlub.pl/
}

\section{The prevalence of selected genes involved in biofilm formation in Candida albicans isolated from the oral cavity}

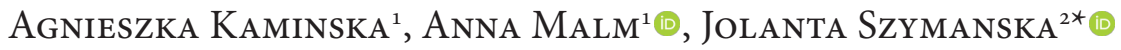 \\ ${ }^{1}$ Chair and Department of Pharmaceutical Microbiology with Laboratory for Microbiological Diagnostics, Medical University of Lublin, \\ Poland \\ ${ }^{2}$ Department of Integrated Paediatric Dentistry, Medical University of Lublin, Poland
}

\begin{tabular}{l}
\hline ARTICLE INFO \\
\hline Received 05 June 2019 \\
Accepted 16 September 2019 \\
\hline Keywords: \\
biofilm, \\
genomics, \\
humans, \\
oral cavity, \\
yeast.
\end{tabular}

\begin{abstract}
Introduction. C. albicans genome sequencing enables investigation of the role of particular genes in biofilm formation involving the yeast-like fungi.

Aim. The aim of the study was to determine the genotypes of $C$. albicans isolates on the basis of the presence of the selected genes involved in biofilm formation.

Material and methods. The study material included C. albicans strains isolated from the oral cavity of 654 healthy individuals. The strain biofilm-forming capacity was estimated with the MTT assay and menadione. The presence of HWP1, ALS3, TUP1, NGR1, SAM2 and CYS3 genes was investigated.
\end{abstract}

Results. In total, 15 gene combinations were found, including nine gene combinations for strains with a confirmed biofilm-forming capacity, 11 - for the strains without this capacity, and five - independent of biofilm-forming capacity. A combination involving all the genes occurred in $72.5 \%$ of all biofilm-forming strains and in $53.8 \%$ of all strains that do not form biofilm. Moreover, the genetic material of $14.3 \%$ of all strains not involved in biofilm formation did not contain any of the studied genes. For one of the biofilmspecies, no analyzed genes were found.

Conclusions.

1. The absence of correlation between gene combinations HWP1, ALS3, TUP1, NGR1, SAM2 and CYS3 and biofilm-forming capacity of the studied C. albicans strains confirms the multigenetic - and not yet fully known - molecular basis of the formation of this structure. This result corresponds to the data reported by other researchers.

2. Knowledge on the genetic foundations of biofilm formation is still developing and the list of biofilm-related genes has been considerably extended.

3. The absence of correlation between the combinations of investigated genes and the biofilm-forming capacity of the studied C. albicans strains confirms a multigenetic, basis of this structure.

4. The research on genes activated or inhibited during biofilm formation is extremely important, because it would enable the development of effective methods to disturb the biofilm forming process at the molecular level. There is a need for such methods in our clinical practice to prevent biofilm formation in the oral cavity.

\section{INTRODUCTION}

The basic factor determining pathogenicity of Candida albicans strains is their biofilm forming capacity, and thus numerous studies aim at an understanding of the mechanisms that control biofilm formation at the molecular level.

\footnotetext{
${ }^{*}$ Corresponding author

e-mail: jolanta.szymanska@umlub.pl
}

Genetic investigations and research into C. albicans genome, conducted over many years, made it possible to acquire the detailed knowledge of the mechanism of biofilm development and of the process of obtaining a unique phenotype by biofilm in vitro $[1,2]$. 


\section{AIM}

The aim of this study was to determine the genotypes of $C$. albicans isolates on the basis of the presence of the selected genes involved in biofilm formation.

\section{MATERIAL AND METHODS}

Buccal swab samples were collected from 654 individuals of both sexes and different ages (Table 1).

The study material (buccal swab samples), immediately after sampling, or after placing in transport medium, was inoculated into Sabouraud's medium with chloramphenicol and ChromAgar Candida. The inoculates were incubated at $35^{\circ} \mathrm{C}$ for 48 hours.

The initial identification of the yeast-like fungi was based on the macroscopic appearance of the colonies on Sabouraud's medium and the growth of coloured colonies on ChromAgar Candida.

The isolates that formed cream-coloured colonies, smooth or with slightly corrugated surface, convex, shiny, smelling of yeast and cream-textured, were used in the further study. Yeast-like fungi were isolated on Sabouraud's medium. The inoculates were incubated at $35^{\circ} \mathrm{C}$ for 48 to 72 hours. The microscopic examination of Gram-stained samples showed Gram-positive thin-walled, spherical, cylindrical or egg-shaped blastospores, 4-6 $\mu \mathrm{m}$ in diameter.

The identification of the most frequently detected Candida species was performed via API 20 C AUX microtest (bioMérieux Polska Sp. z o.o., Poland).

The capacity of the studied $C$. albicans isolates to form biofilm in vitro were examined in stationary conditions with the MTT assay with menadione, generally used in screening tests.

The selected genes were identified: HWP1, ALS3, TUP1, $N G R 1, S A M 2$, and $C Y S 3$, involved in biofilm formation by C. albicans strains isolated from oral ontocenosis in healthy individuals from different age groups. The PCR reaction was performed in $15 \mu \mathrm{l}$ of mixture (Table 2); its composition differed only in primers, according to the gene we looked for.

Table 1. Tested populations

\begin{tabular}{|l|c|c|}
\hline \multicolumn{1}{|c|}{ Tested group } & $\begin{array}{c}\text { Age interval } \\
\text { (years) }\end{array}$ & $\begin{array}{c}\text { Number } \\
\text { of people }\end{array}$ \\
\hline Neonates, infants, nursery children & $0-3$ & 102 \\
\hline Kindergarten children & $4-6$ & 82 \\
\hline Primary school children & $7-14$ & 91 \\
\hline Secondary school youth & $15-18$ & 101 \\
\hline University students & $19-25$ & 92 \\
\hline Professionally active individuals & $26-45$ & 79 \\
\hline $\begin{array}{l}\text { Professionally active individuals, } \\
\text { pensioners and retired persons }\end{array}$ & $46-65$ & 53 \\
\hline Nursing home clients & $\geq 66$ & 54 \\
\hline
\end{tabular}

Table 2. PCR mixture composition

\begin{tabular}{|c|c|}
\hline Volume & Reagents \\
\hline $7.5 \mu \mathrm{l}$ & REDTaq Ready Mix \\
\hline $0.75 \mu \mathrm{l}$ & Forward primer \\
\hline $0.75 \mu \mathrm{l}$ & Reverse primer \\
\hline $1 \mu \mathrm{l}$ & DNA Matrix \\
\hline $5 \mu \mathrm{l}$ & Water \\
\hline
\end{tabular}

Primer sequences for the studied genes were followed: $H W \mathrm{P} 1$

5'-TCAGTTCCACTCATGCAACCA-3'

5'-AGCACCGAAAGTCAATCTCATGT-3'

ALS3

5'-GTGATGCTGGATCTAACGGTATTG-3'

5'-GTCTTAGTTTTGTCGCGGTTAGG-3'

TUP1

5'-GCTTCAGGTAACCCATTGTTGAT-3'

5'-CTTCGGTTCCCTTTGAGTTTAGG-3'

$N R G 1$

5'-CACCTCACTTGCAACCCC-3'

5'-GCCCTGGAGATGGTCTGA-3'

SAM2

5'-GGTTCCTTGCCATGGTTGAG-3'

5'-TTGTGTCGACTCTTTTTGGGATAA-3'

CYS3

5'-GTGGTATCGAGTCGTTGATCGA-3'

5'-ACCATTGGCTTCTCTTTCTTCCT-3'

The samples were placed in a thermocycler and the following amplification programs were set:

- $95^{\circ} \mathrm{C}$ for 5 minutes - initial denaturation,

- 30 cycles including the following stages:

$94^{\circ} \mathrm{C}$ for 1 minute - denaturation,

$60^{\circ} \mathrm{C}$ for 1 minute - starter annealing,

$72^{\circ} \mathrm{C}$ for 1 minute - elongation,

- $72^{\circ} \mathrm{C}$ for 10 minutes - final elongation,

- $4^{\circ} \mathrm{C}$ for 20 hours, if the amplification was set for the night.

The amplified PCR products were electrophoresed in $2 \%$ agarose gel with $20 \mu \mathrm{l}$ of ethidium bromide, in TBE buffer, at the voltage of $120 \mathrm{mV}$. In each gel, we also separated 1 kb DNA markers (100 bp DNA Ladder): 100, 200, 300, $400,500,600,700,800,900,1000$ base pairs. To visualize the PCR product, the gels were placed in a transiluminator and the photographs were archived in the electronic form and as printouts (Fig. 1).

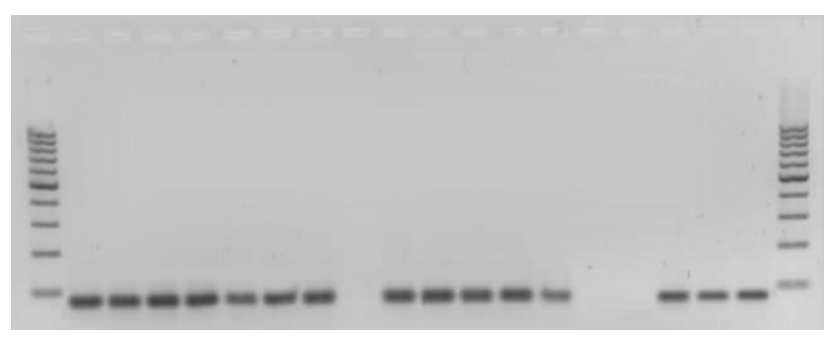

Figure 1. Electropherogram of PCR products stripe pattern for C. albicans stripes isolated from the oral ontocenosis of healthy individuals

\section{RESULTS}

The oral cavity ontocenosis in the studied population was colonized mainly by the yeast-like fungi of the $C$. albicans genus; they were found in $160(24.5 \%)$ individuals. Using the MTT assay with menadione we showed that 69 (43\%) of the C. albicans isolates from oral mucosa in the tested population were capable of forming biofilm. We found 
15 gene combinations, nine for the strains with a confirmed biofilm formation capacity, and 11 for the non-biofilm forming strains. It must be noted that the biofilm forming strains and the non-biofilm forming ones had five combinations in common.

The most frequent combination, involving all the studied genes: HWP1, ALS3, TUP1, NRG1, SAM2, CYS3 (Fig. 2), was found in $50(72.5 \%)$ biofilm forming strains (Table 3 ) and in 49 (53.8\%) non-biofilm forming strains (Table 4). Moreover, gene $S A M 2$ was relatively frequent; it was found in $8(11.6 \%)$ strains with the confirmed biofilm forming capacity (Table 3 ) and in $13(14.3 \%)$ of the non-biofilm forming strains (Table 4).

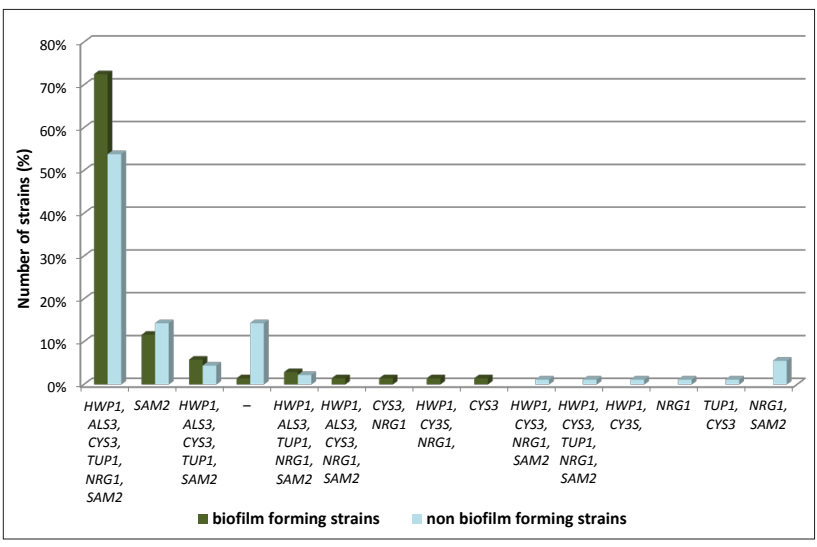

Figure 2. Genes present in C. albicans strains isolated from the oral ontocenosis of healthy individuals from different age groups

Table 3. The distribution of gene combinations in C. albicans biofilm forming strains isolated from the oral ontocenosis in healthy individuals from different age groups

\begin{tabular}{|c|c|c|c|c|c|c|c|c|c|}
\hline \multirow{2}{*}{ Gene combination } & \multicolumn{8}{|c|}{ Number of strains in age groups } & \multirow{2}{*}{\begin{tabular}{|c|} 
Number \\
(percentage) \\
of strains \\
$69(100 \%)$ \\
\end{tabular}} \\
\hline & 0 & 1 & 2 & 3 & 4 & 5 & 6 & 7 & \\
\hline $\begin{array}{l}\text { HWP1, ALS3, CYS3, } \\
\text { TUP1, NRG1, SAM2 }\end{array}$ & 3 & 4 & 6 & 7 & 6 & 9 & 6 & 9 & $50(72.5 \%)$ \\
\hline SAM2 & 1 & 2 & 2 & & & 3 & & & $8(11.6 \%)$ \\
\hline $\begin{array}{l}\text { HWP1, ALS3, CYS3, } \\
\text { TUP1, SAM2 }\end{array}$ & 1 & & & 1 & 2 & & & & $4(5.8 \%)$ \\
\hline $\begin{array}{l}\text { HWP1, ALS3, CYS3, } \\
\text { NRG1, SAM2 }\end{array}$ & 1 & & & & & & & & $1(1.45 \%)$ \\
\hline- & & & 1 & & & & & & $1(1.45 \%)$ \\
\hline CYS3, NRG1 & & & & 1 & & & & & $1(1.45 \%)$ \\
\hline HWP1, CY3S, NRG1, & & & & 1 & & & & & $1(1.45 \%)$ \\
\hline $\begin{array}{l}\text { HWP1, ALS3, TUP1, } \\
\text { NRG1, SAM2 }\end{array}$ & & & & & & & 1 & 1 & $2(2.9 \%)$ \\
\hline CYS3 & & & & & & & & 1 & $1(1.45 \%)$ \\
\hline
\end{tabular}

As it is shown in Tables 3 and 4, other combinations were present in very few isolates. It is interesting that the genetic material of $13(14.3 \%)$ of the non-biofilm forming strains and one of the biofilm forming strains did not contain any of the studied genes. It should be emphasized that the combination prevailing in the total studied strains was also most frequent in the strains isolated in different age groups, regardless of their biofilm forming capacity.

The complete list of the genotypes of $C$. albicans strains isolated from the oral ontocenosis of healthy individuals from different age groups, correlated with the yeast-like fungi biofilm forming capacity, can be obtained from the authors.
Table 4. The distribution of gene combinations in C. albicans non-biofilm forming strains isolated from the oral ontocenosis in healthy individuals from different age groups

\begin{tabular}{|c|c|c|c|c|c|c|c|c|c|}
\hline \multirow{2}{*}{ Gene combination } & \multicolumn{8}{|c|}{ Number of strains in age groups } & \multirow{2}{*}{$\begin{array}{c}\text { Number } \\
\text { (percentage) } \\
\text { of strains } \\
91(100 \%) \\
\end{array}$} \\
\hline & 0 & 1 & 2 & 3 & 4 & 5 & 6 & 7 & \\
\hline $\begin{array}{l}\text { HWP1, ALS3, CYS3, } \\
\text { TUP1, NRG1, SAM2 }\end{array}$ & 8 & 5 & 7 & 4 & 4 & 4 & 10 & 7 & $49(53.8 \%)$ \\
\hline SAM2 & 2 & 4 & 1 & & 4 & 1 & 1 & & $13(14.3 \%)$ \\
\hline $\begin{array}{l}\text { HWP1, ALS3, CYS3, } \\
\text { TUP1, SAM2 }\end{array}$ & & 1 & & 3 & & & & & $4(4.4 \%)$ \\
\hline- & & 3 & 3 & 2 & 3 & & & 2 & $13(14.3 \%)$ \\
\hline $\begin{array}{l}\text { HWP1, ALS3, TUP1, } \\
\text { NRG1, SAM2 }\end{array}$ & & 1 & & & & & 1 & & $2(2.2 \%)$ \\
\hline $\begin{array}{l}\text { HWP1, CYS3, NRG1, } \\
\text { SAM2 }\end{array}$ & 1 & & & & & & & & $1(1.1 \%)$ \\
\hline $\begin{array}{l}\text { HWP1, CYS3, TUP1, } \\
\text { NRG1, SAM2 }\end{array}$ & & & 1 & & & & & & $1(1.1 \%)$ \\
\hline HWP1, CY3S, & & & & 1 & & & & & $1(1.1 \%)$ \\
\hline NRG1 & & & & 1 & & & & & $1(1.1 \%)$ \\
\hline TUP1, CYS3 & & & & & 1 & & & & $1(1.1 \%)$ \\
\hline NRG1, SAM2 & & & & & 2 & 3 & & & $5(5.5 \%)$ \\
\hline
\end{tabular}

\section{DISCUSSION}

A basic determinant of pathogenicity of C. albicans strains is their capacity to form biofilm, and, therefore, the aim of numerous studies was to understand the processes that control biofilm formation at the molecular level. To date, we have discovered a large and still growing list of $C$. albicans genes whose products affect, or may affect, biofilm development in vivo and/or in vitro. Mutant libraries with deletion of the genes that transcribe individual transcription factors are being developed, as the latter play a principal role in life processes regulation, including biofilm formation control [3]. The analysis of transcription profiles using DNA microarrays points to the presence of genes closely related to biofilm phenotype. All the stages of biofilm formation, including adhesion, are under control of transcription factors, e.g.: Efg1, Cph1, Tec1, Bcr1, and are determined by their activity. A contact of $C$. albicans with a particular surface is a signal activating, among others, MAPK signalling cascade, which initiates transcription factors and expression of a specific set of genes for a given phase of biofilm development. After contact of C. albicans with a polystyrene surface, a surprising increase can be observed in the level of transcription of sulphur metabolism genes that encode amino acids: methionine and cysteine, and of CDR 1 and MDR 1 genes that encode the mechanism of active efflux of drugs through cellular membranes. The formation of biofilm structure is conditioned by the expression of many genes. The most important of these include: BCR1, TEC1, ALS3, HWP1, ALS2 (which encode proteins participating in the adhesion process), EFG1, TEC1, SUV3, NUP8, MDS3, KEM3, MKC1 (which encode proteins participating in the process), or CHK1, YWP1 (which encode proteins responsible for intercellular communication). Genes such as: NRG1, SAM2, CYS3 and TUP1 also take part in biofilm formation [4,5]. Genes $H W P 1$ and $A L S 3$, analysed in this study, encode adhesins present on pseudo-hyphae/ hyphae. Genes NRG1 and TUP1 are negative regulators of the filamentation process, while genes SAM2 and CYS3 are involved in a biosynthesis of sulphur amino acids that 
are important for yeast-like fungi cells in mature biofilm [2,6-12].

Five common gene combinations were found, regardless of the biofilm formation capacity of the tested isolates. The combination containing all the mentioned genes occurred most frequently; in addition, SAM2 was found relatively often. It is worth noting that a strain of $C$. albicans that did not contain any of the studied genes was also found.

It is known that adhesion is an indispensable stage of biofilm formation. Herein, Als proteins (Als1-Als 9), i.e. the products of $A L S$ genes family, belong among the basic C. albicans adhesins $[2,13,14]$. On the surface of pseudohyphae/hyphae, additional adhesins, among others, the Hwp1 protein encoded by gene $H W P 1$, can also be found. Genes $A L S$ and HWP1 are expressed during blastospore-topseudo-hypha morphogenesis. However, both adhesins: Als3 and Hwp1, are not always necessary for biofilm formation $[2,5,10,15,16]$.

The literature data and the results of the present study suggest that the process of $C$. albicans adhesion is very complex, and many adhesins and particles participate in coadhesion with other oral microbes. In addition, it is known that not all biofilm forming strains of $C$. albicans are capable of blastospore-to-psuedo-hyphae/hyphae transformation, despite the fact that Candida are dimorphic fungi, their dimorphism being an important factor of their pathogenicity $[17,18]$.

The representative results obtained in the present study (due to a large number of healthy individuals at all the age groups and of both sexes) in the aspect of the participation of the selected genes that condition biofilm formation in C. albicans in the context of possible pathological conditions.

\section{CONCLUSIONS}

1. The absence of correlation between gene combinations HWP1, ALS3, TUP1, NGR1, SAM2 and CYS3 and biofilm-forming capacity of the studied $C$. albicans strains confirms the multigenetic - and not yet fully known - molecular basis of the formation of this structure. This result corresponds to the data reported by other researchers.

2. The knowledge on the genetic foundations of biofilm formation is still developing and the list of biofilm-related genes has been considerably extended.

3. The absence of correlation between the combinations of investigated genes and the biofilm-forming capacity of the studied C. albicans strains confirms a multigenetic, basis of this structure.

4. The research on genes activated or inhibited during biofilm formation is extremely important, because it would enable the development of effective methods to disturb the biofilm forming process at the molecular level. There is a need for such methods in our clinical practice to prevent biofilm formation in the oral cavity.

\section{ACKNOWLEDGEMENTS}

The study was performed under the framework of the statutory activity of the Medical University of Lublin, Poland.

\section{ORCID iDs}

Anna Malm (Dhttps://orcid.org/0000-0003-1503-7634

Jolanta Szymańska (1) https://orcid.org/0000-0002-9917-2907

\section{REFERENCES}

1. Finkel JS, Mitchell AP. Genetic control of Candida albicans biofilm development. Nat Rev Microbiol. 2011;9(2):109-18.

2. Nobile CJ, Mitchell AP. Genetics and genomics of Candida albicans biofilm formation. Cell Microbiol. 2006;8(9):1382-91.

3. Mnichowska-Polanowska M, Giedrys-Kalemba S. Methods and techniques used in Candida biofilm research (in Polish). Mikol Lek. 2009;16(4):238-42.

4. Li F, Svarovsky MJ, Karlsso AJ, et al. Eaplp, an adhesin that mediates Candida albicans biofilm formation in vitro and in vivo. Eucaryot Cell. 2007;6:931-9.

5. Mnichowska-Polanowska M, Kaczała M, Giedrys-Kalemba S. The characteristic of Candida biofilm (in Polish). Mikol. Lek. 2009;16(3):159-64.

6. Ahariz M, I Loeb, P Courtois. Oral candidiasis and dentures. Rev Stomatol Chir Maxillofac. 2010;111(2):74-8.

7. Blankenship J, Mitchell A. How to build a biofilm: a fungal perspective. Curr Opin Microbiol. 2006;9(6):588-94.

8. Karkowska-Kuleta J, Rapala-Kozik M, Kozik A. Fungi pathogenic to humans: molecular bases of virulence of Candida albicans, Cryptococcus neoformans and Aspergillus fumigatus. Acta Biochem Pol. 2009;56(2):211-24.

9. Kebaara B, Langford M, Navarathna D, et al. Candida albicans Tup1 involved in farnesol - mediated inhibition of filamentous-growth induction. Eukaryot Cell. 2008;7(6):980-7.

10. De Sordi L, Muhlschlegel F. Quorum sensing and fungal - bacterial interactions in Candida albicans: a communicative network regulating microbial coexistence and virulence. Yeast Res. 2009;9(7): 990-9.

11. Uppuluri P, Chaturvedi AK, Lopez-Ribot J. Design of simple model of Candida albicans biofilm formed under conditions of flow: development, architecture and drug resistance. Mycopathologia 2009;168(3):101-9.

12. Uppuluri P, Pierce C, Thomas D, et al. The transcriptional regulator Nrglp controls Candida albicans biofilm formation and dispersion. Eukaryot Cell. 2010;9(10):1531-7.

13. Chandra J, Kuhn DM, Mukherjee PK, et al. Biofilm formation by the fungal pathogen Candida albicans: development, architecture, and drug resistance. J Bacteriol. 2001;183:5385-94.

14. Ten Cate JM, Klis FM, Pereira-Cenci T, Crielaard W. Molecular and cellular mechanisms lead to Candida biofilm formation. J Dent. Res. 2009;88(2):105-15.

15. Ene IV, Bennett RJ. Hwp1 and related adhesins contribute to both miting and biofilm formation in Candida albicans. Eukaryot Cell. 2009;12:1909-13.

16. Soll D. Why does Candida switch? Yeast Res. 2009;9(7):1-17.

17. Barnett JA. A history of research on yeasts 12: medical yeasts part I, Candida albicans. Yeast. 2008;25:385-417.

18. Wächtler B, Wilson D, Haedicke K, Dalle F, Hube B. From attachment to damage: defined genes of Candida albicans mediate adhesion, invasion and damage during interaction with oral epithelial cells. PLoS ONE. 2011;6(2). https://doi.org/10.1371/journal. pone.0017046.s 